\title{
ESPAÇO GEOGRÁFICO E PERCEPÇÕES: COMPREENSÕES DE UM DEFICIENTE VISUAL
}

\author{
Diego Salomão Candido de O. Salvador ${ }^{1}$, Aglene de Arruda Moreira ${ }^{2}$, Bruno Lima de \\ Brito $^{3}$ \\ ${ }^{1}$ Graduando do curso de Licenciatura Plena em Geografia do Centro Federal de Educação \\ Tecnológica do Rio Grande do Norte (CEFETRN) \\ diegolisse@yahoo.com.br \\ ${ }^{2}$ Graduando do curso de Licenciatura Plena em Geografia do CEFETRN \\ ag_cefet@yahoo.com.br \\ ${ }^{3}$ Estudante da rede estadual de ensino na Cidade do Natal-RN
}

Recebido em maio de 2006 e aceito em outubro de 2006

\begin{abstract}
RESUMO
Compreender os espaços geográficos é fator de suma importância. Isso é dito em função do espaço geográfico ser o produto das relações dos homens entre si e com o meio onde vivem. Dessa maneira, compreender os espaços é assimilar as diferentes formas que o homem tem de habitar, experimentar e viver, sempre procurando suprir as suas necessidades. Para obter essa compreensão de maneira significativa é necessário vivenciar diferentes espaços, buscando tecer reflexões acerca desses. Isso é dito através da adoção da postura metodológica da fenomenologia, com traços de criticidade, trabalhando com descrições e análises de elementos e experiências sociais. Com isso, o estudo em tela traz a compreensão espacial de um deficiente visual, que é realizada através das percepções de três espaços geográficos diferentes, localizados na Cidade do Natal-RN: Avenida Senador Salgado Filho, Shopping Midway Mall e Parque das Dunas. As percepções desses três espaços desencadearam reflexões que enriqueceram as compreensões espaciais do deficiente visual. Além disso, as vivências de diferentes espaços geográficos fizeram com que as suas conceituações de espaço fossem (re)formuladas.
\end{abstract}

PALAVRAS-CHAVE: Espaço geográfico. Percepções. Reflexões. Compreensões espaciais. Inclusão.

\section{GEOGRAPHIC SPACE AND PERCEPTIONS: UNDERSTANDING OF A BLIND}

\section{ABSTRACT}

To understand the geographic spaces is factor of utmost importance. This is said in function of the geographic space to be the product of the relations of the men between themselves and with the way where they live. In this way, to understand the spaces is to always understand the different forms that the man has to inhabit, to try and to live, looking for to supply its necessities. To get this understanding in significant way it is necessary to live deeply different spaces, being searched to weave reflections concerning these. This is said through the adoption of the methodological position of the phenomenology, with features critics, working with descriptions and analyses of the elements and experiences socials. With this, the study in screen it brings the space understanding of a blind, that is carried through the perceptions of three different geographic spaces, located in Natal-RN city. The perceptions of these three spaces had 
unchained reflections that had enriched the space understandings of the blind. Besides, the experiences of different geographic spaces had made with that its conceptualizations of space were (re)formulated.

KEY-WORDS: Geographic space. Perceptions. Reflections. Space understandings. Inclusion. 


\section{ESPAÇO GEOGRÁFICO E PERCEPÇÕES: COMPREENSÕES DE UM DEFICIENTE VISUAL}

\section{PALAVRAS INICIAIS}

O estudo em tela trata da compreensão espacial de um deficiente visual. Para isso, são abordadas reflexões sobre o espaço geográfico e as suas percepções, além do relato de experiências de percepção de diferentes espaços, realizadas por uma pessoa com deficiência visual.

O trabalho está sistematizado em quatro momentos: no primeiro realizam-se reflexões sobre o objeto de estudo da Geografia, o espaço geográfico; no segundo apresentam-se abordagens acerca das percepções do espaço geográfico; no terceiro são colocados em tela pensamentos sobre as percepções espaciais de um deficiente visual, quando se descreve as experiências em diferentes espaços geográficos realizadas com o deficiente; e no quarto momento são apresentadas as considerações finais do trabalho, ratificando algumas discussões importantes presentes no desencadear desse.

\section{O ESPAÇO NA CIÊNCIA GEOGRÁFICA}

A Geografia é uma ciência que tem por objeto de estudo o espaço geográfico. Mas nem sempre esse foi considerado o objeto científico dessa ciência. Santos (2004) destaca que, por muito tempo, a Geografia foi viúva do espaço, sendo caracterizada pelos estudos meramente naturalistas (escolas tradicionais) e estatísticos (escola teoréticaquantitativista). Durante esse tempo, essa ciência era vista como não possuidora de um objeto de estudo, mas como responsável por sínteses que englobariam conceitos e objetos de inúmeras outras ciências. Com isso, o desenvolvimento epistemológico da Geografia encontrou múltiplos obstáculos, devido à pretensão de se fazer sínteses abarcadoras de vários conceitos e objetos científicos, sem remeter-se aos seus próprios conceitos e ao seu próprio objeto de estudo.

Com o despontar dos estudos críticos na Geografia, a partir da década de 1970, no Brasil, que passaram a atentar com maior intensidade para a inter-relação dos elementos sociais e naturais, tendo o humano como fator preponderante na vivência e produção dos espaços, essa ciência passou a possuir um objeto de estudo definido: o espaço geográfico. Santos (2004) destaca que a definição de um objeto de estudo para a Geografia foi de suma importância para o seu desenvolvimento, em função de ser inadmissível a existência de uma ciência sem um objeto de estudo definido para ser alvo de descrições e reflexões.

Portanto, as reflexões aqui tecidas mensuram para o objeto geográfico, no caso o espaço geográfico. As reflexões acerca desse são calcadas nas seguintes indagações: o que é o espaço geográfico? O que esse compreende? Como é formado? Qual a sua importância?

Definir o espaço geográfico não é tarefa fácil, em função desse abarcar elementos de ordem natural, social, material, imaterial e emocional. Pode-se dizer que o espaço é um conjunto, dado através da história, de relações e formas, sendo constituído por instâncias sociais, econômicas, políticas, culturais, históricas, naturais, dentre outras. As palavras de 
Santos (2004, p. 153) expressam significativamente o que aqui se pensa acerca do espaço geográfico, quando diz que esse é

[...] um conjunto de relações realizadas através de funções e de formas que se apresentam como testemunho de uma história escrita por processos do passado e do presente. Isto é, o espaço se define como um conjunto de formas representativas de relações sociais do passado e do presente e por uma estrutura representada por relações sociais que estão acontecendo diante dos nossos olhos e que se manifestam através de processos e funções. O espaço é, então, um verdadeiro campo de forças cuja aceleração é desigual. Daí porque a evolução espacial não se faz de forma idêntica em todos os lugares.

O espaço geográfico compreende objetos, ações, emoções e razões (SANTOS, 1996). Os objetos são referentes aos elementos materiais presentes no espaço, os quais são pensados e elaborados pelos homens. Já as ações, emoções e razões, como também os objetos, referem-se aos sujeitos principais do espaço, os seres humanos. Estes são responsáveis pela estruturação espacial, que ocorre através das vivências, ou seja, da elaboração dos objetos e dos relacionamentos dos humanos entre si e com a natureza, o que envolve a razão, a emoção e a ação. Em função dessa complexidade estrutural do espaço, Bettanini (1982) declara que esse deve ser pensado e compreendido sempre no plural.

A construção espacial é uma obra social que acontece temporalmente, isto é, durante a história. O espaço existe por meio de uma sociedade que o encarna, o constrói e o vive. Gomes (1996) afirma que o espaço deve ser entendido como aquele que é vivido, construído e representado pelos atores sociais que nele circulam. Moraes (1994, p. 35), destacando a influência da vivência humana sobre as formas espaciais, corrobora com esse pensamento, quando afirma que "[...] as formas espaciais criadas pelos homens expressam muito das relações sociais [...] que foram produzidas [vivenciadas]”. Portanto, o espaço é uma construção social, que expressa as relações dos humanos entre si e com a natureza, durante a história.

Por último, resta compreender qual a importância do espaço. Para isso, é necessário assimilar que é nele que os homens vivem, expressam-se, relacionam-se e produzem. O espaço é uma construção social, calcada na razão, na emoção e na ação. Em suma, diz-se que espaço é sociedade. Dessa maneira, compreender o espaço é apreender as relações dos homens entre si e com o meio circundante, o que é imprescindível. Portanto, a importância do espaço refere-se ao fato desse ser uma expressão social que vale ser entendida.

\section{ESPAÇO GEOGRÁFICO E PERCEPÇÕES}

Para realizar reflexões que inter-relacionem o espaço geográfico às percepções, toma-se como ancoragem os pensamentos de Oliveira (2001). Esses pensamentos ajudarão a desvendar os seguintes questionamentos: o que é percepção? Qual a importância da percepção espacial? Como se dá essa percepção? A que se relaciona a percepção espacial?

A percepção é decorrente de conhecimentos sensíveis acrescidos de significação. É extremamente ligada a vivência humana, sendo, portanto, bastante complexa e subjetiva, 
não havendo, dessa maneira, uma homogeneidade de percepções. Oliveira define a percepção como sendo uma apreensão sensível acompanhada por qualidades humanas, ou seja, por significações subjetivas. Essas significações são importantíssimas, juntamente com os conhecimentos sensíveis, para o estudo e compreensão dos mais variados espaços geográficos. Em outras palavras, porém com a mesma lógica, também pode-se dizer que percepção é a exteriorização de sentimentos e pontos de vista internos aos humanos (TUAN, 1980).

A importância das percepções nos estudos sobre os espaços geográficos decorre da complexidade e subjetividade que essas apresentam. Sabe-se que o espaço é uma construção social, portanto, também próprio dessas peculiaridades. Dessa forma, a compreensão espacial é estritamente ligada à análise e reflexão das percepções dos sujeitos espaciais, os quais devem ser pensados e considerados como pessoas que têm opiniões diferenciadas e não como simples objetos estatísticos.

A percepção espacial se dá por meio dos aparelhos sensoriais humanos, através da tonalidade de cores, dos sons, das acuidades olfativas, gustativas e táteis, e da visão. Oliveira caracteriza a percepção do espaço geográfico como sendo multifacetada, dando-se quase que inteiramente, segundo a autora, pelo sentido da visão. Todavia, esse pensamento, que expressa uma visão determinista amplamente presente nas concepções geográficas acerca das percepções espaciais, é colocado em xeque quando se analisa as percepções de um deficiente visual, que se utiliza com bastante significância dos outros sentidos à parte do da visão, não deixando de realizar uma apurada descrição e reflexão dos espaços em que vive e/ou sente. Por isso, não se pode declarar que as percepções geográficas se dão quase que inteiramente pelo sentido da visão, por que se estará excluindo a importância de outros sentidos sensoriais, que também são extremamente relevantes para essas. Hernandez (2000) diz que o momento em que se vive é o da cultura visual, aquele em que tudo e todos são analisados pelo o que se vê. Todavia, o autor coloca que mesmo vivendo-se nessa cultura, não se pode negar e esquecer que as análises, na maioria das vezes, ultrapassam o sentido da visão, relacionando outros sentidos humanos.

Destaca-se que a percepção subordina-se a cognição, isto é, a inteligência ${ }^{1}$. Pode-se até dizer que a percepção é essencialmente egocêntrica, ou seja, ligada a posição do sujeito que percebe, sendo um elemento de extrema individualidade. Por isso, afirma-se que quando se trabalha com percepção se está trabalhando, conseqüentemente, com subjetividade ${ }^{2}$. Isso é extremamente valioso para as reflexões espaciais.

Em suma, afirma-se que os estudos geográficos que pretendem ultrapassar o gabinete, isto é, o meramente teórico, devem também considerar as percepções humanas, as quais revelam riqueza e complexidade de concepções.

\footnotetext{
${ }^{1}$ Esse pensamento é explicitado na teoria sobre as percepções humanas de Piaget. Essa teoria destaca um elo indissociável entre as percepções, os pensamentos e a inteligência humana. Esse elo não se dá de forma linear, mas de acordo com as experiências de cada um.

2 “A subjetividade [...] é um dos traços mais marcantes do humanismo e deriva diretamente [...] [da] concepção antropocêntrica” (GOMES, 1996, p. 310).
} 


\section{COMO UM DEFICIENTE VISUAL PERCEBE O ESPAÇO GEOGRÁFICO}

Após as reflexões acerca do espaço geográfico e percepções, serão realizadas agora considerações sobre as percepções espaciais de um deficiente visual.

Compreender as percepções e o entendimento acerca do espaço por parte de um deficiente visual é de importância ímpar, em função de pouco se atentar no meio científico da Geografia para essa compreensão. Para isso, antes de se descrever as percepções do deficiente visual acerca do espaço geográfico, é válido tecer reflexões calcadas nas seguintes indagações: como se dá a percepção do espaço geográfico por um deficiente visual? No que alicerça-se a compreensão espacial desse?

De acordo com Almeida e Passini (1989), as crianças percebem o espaço envolvendo traços muito próximos do real, diferentemente dos adultos que procuram sempre encontrar referenciais para as suas percepções. Diz-se aqui que a percepção espacial dos deficientes visuais é amplamente ligada aos seus imaginários, bem como a todos os sentidos sensoriais que possuem. A utilização dos sentidos da audição, do tato, do olfato e do paladar, juntamente com o imaginário, faz com que os deficientes visuais formem os seus próprios referenciais do espaço, alcançando com isso percepções bem próximas do que há de fato no real.

A compreensão espacial não deve fundamentar-se apenas em conceituações. As experiências, isto é, as vivências são de extrema importância para essa compreensão. O espaço geográfico é complexo, exigindo que a sua compreensão seja permeada por experiências e conceituações. No caso específico dos deficientes visuais, diz-se que é imprescindível a realização de experiências, dando bastante atenção às suas vivências, para o enriquecimento e a (re)formulação das suas reflexões acerca do espaço geográfico. Dessa maneira, as percepções espaciais de um deficiente visual aqui descritas seguirão essa lógica: serão realizadas experiências para o enriquecimento e a (re)formulação das conceituações.

O desejo de se trabalhar com as percepções espaciais de um deficiente visual surgiu com a vivência em um programa ${ }^{3}$ que contou com o trabalho de bolsistas videntes e com um bolsista cego. Com essa vivência percebeu-se a impressionante riqueza de percepções que envolve a compreensão espacial por parte dos deficientes visuais, despertando o interesse de se aprofundar e relatar essa compreensão.

As percepções espaciais aqui descritas são realizadas pelo bolsista cego desse programa. Ele é aluno do segundo ano do Ensino Médio na rede pública estadual de ensino na Cidade do Natal, capital do Rio Grande do Norte. Nunca teve acesso ao sentido da visão e, portanto, o seu imaginário é bem diferente do de uma pessoa que tornou-se cega durante sua vivência. Nas suas percepções, utiliza-se imensamente dos sentidos da audição, do tato

\footnotetext{
${ }^{3} \mathrm{O}$ intitulado "Programa de formação continuada de docentes para um sistema educativo inclusivo, com ênfase na deficiência visual”, foi realizado durante os meses de janeiro a agosto de 2006, no Núcleo de Inclusão do CEFETRN (Centro Federal de Educação Tecnológica do Rio Grande do Norte), tendo como objetivo capacitar professores das redes públicas de ensino da Cidade do Natal-RN, para aperfeiçoarem as suas práticas docentes em relação aos alunos deficientes visuais e, conseqüentemente, aos alunos com outras deficiências, como também aos videntes. Nesse programa, trabalharam com os professores do CEFETRN cinco bolsistas, sendo que um deles é cego. Ele teve função primordial no programa, sendo responsável pelo primeiro teste dos materiais didáticos táteis confeccionados para ajudarem na prática docente dos professores que participaram do programa.
} 
e do olfato, bem como do seu imaginário, que constitui-se através da utilização dos seus sentidos e do relato da compreensão espacial de pessoas videntes que lhe acompanham.

O trabalho com esse deficiente visual foi realizado nos meses de abril e maio de 2006, sendo dividido em dois momentos: no primeiro visitou-se três espaços diferenciados, todos localizados em Natal-RN, e analisou-se as suas percepções acerca desses; no segundo procurou-se a (re)formulação das conceituações de espaço geográfico expressas por ele antes das experiências nos três espaços. Dessa maneira, as suas percepções serão aqui descritas a partir desses dois momentos. Destaca-se que a postura metodológica adotada aqui é a da fenomenologia, com traços de criticidade ${ }^{4}$. Isto é, a postura que considera descrições e análises de elementos e experiências sociais, sempre buscando ultrapassar aquilo que aparece, ou seja, procurando ir para além das aparências. Os aportes teóricos sobre essa postura metodológica adotada são Relph (1988), Gomes (1996) e Santos (1996 e 2004).

\subsection{EXPERIÊNCIAS}

Sabe-se que o espaço geográfico é produto das relações dos homens entre si e com o meio em que vivem. Essas relações não são lineares, pelo contrário, sendo marcadas por subjetividades, particularidades e complexidades. Isso faz com que existam diversos espaços geográficos, os quais apresentam peculiaridades que se inter-relacionam com a forma pela qual os homens os habitam, relacionam e utilizam.

Com isso, houve a preocupação de vivenciar com o deficiente visual três espaços geográficos com características diferentes entre si. Isso desencadeou percepções marcadas também por diferenças, o que tornou a compreensão espacial bastante rica e apurada.

$\mathrm{Na}$ visita aos três espaços foram feitas ao deficiente visual três perguntas que ajudaram no desencadeamento das suas percepções. Essas perguntas foram as seguintes: que sons você percebe neste espaço? Que odores você sente neste espaço? Qual a sua compreensão do espaço visitado?

As vivências espaciais com o deficiente ocorreram nos seguintes trajetos (ilustração 01): primeiro, visitou-se uma delimitação da Avenida Senador Salgado Filho, sendo que se saiu da frente do CEFETRN dirigindo-se até a frente do Supermercado Nordestão, quando se voltou em direção ao Shopping Midway Mall, utilizando-se das ruas Antônio Basílio e Dr. José Gonçalves, que ficam próximas da avenida; logo após, entrou-se no shopping supracitado, o qual constitui-se no segundo trajeto; por último, vivenciou-se o Parque das Dunas, no caso o terceiro trajeto. A descrição das experiências em cada trajeto é realizada a seguir.

\subsubsection{PRIMEIRO TRAJETO}

O primeiro espaço geográfico percebido é marcado pela intensa circulação de automóveis e pessoas, constituindo-se em um típico exemplo de espaço urbano. Esse está inserido na Avenida Senador Salgado Filho, em Natal-RN. Delimitou-se nessa avenida um percurso a ser vivenciado, o qual já foi citado anteriormente.

\footnotetext{
4 “A finalidade desta conduta [de unir a fenomenologia a análises críticas] é compreender a sociedade em seus aspectos fundamentais, suas determinações, leis e regras de evolução” (GOMES, 1996, p. 282-283).
} 
Inicialmente, o deficiente percebeu o grande barulho existente no espaço, decorrente da intensa circulação de automóveis que há nesse. Por causa desse barulho, ele declarou não conseguir perceber com facilidade a presença de pessoas circulando, o que tornou a sua locomoção dificultosa. Essa locomoção tornou-se ainda mais complicada em função da falta de apropriação das calçadas do espaço, que são muito próximas da avenida e possuem intensos e constantes desníveis. Além disso, ele destacou a grande dificuldade de formular referenciais nesse espaço, em função da sua grande desorganização.

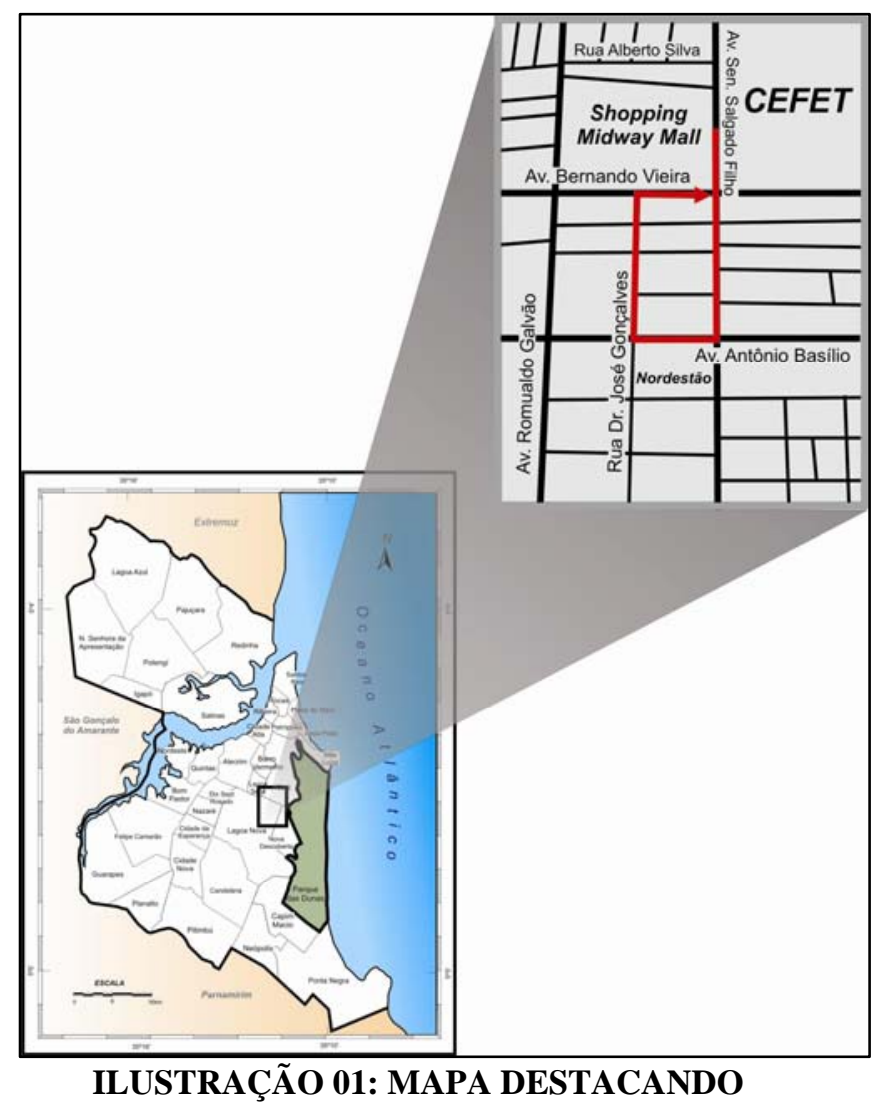
OS TRAJETOS PERCEBIDOS.

Organização de Diego Salomão C. O. Salvador, 2006.

Cartografia de Josué Alencar Bezerra, 2006.

Afirmou que a sua locomoção, como a de outros deficientes visuais, no espaço é impossível de ser realizada com segurança sem que ele esteja acompanhado por uma pessoa vidente, em função de não haver nenhuma apropriação para a locomoção de deficientes visuais, bem como para outros deficientes. Declarou ainda que o espaço melhoraria para todos se fossem instalados sinais sonoros e realizados aplainamentos nas suas calçadas. Destaca-se que a desorganização desse espaço é tão intensa que a locomoção de pessoas videntes é também difícil de ser realizada.

Os odores percebidos foram vários. Em função de o espaço ser explicitamente urbano, foram sentidos odores de lixo, poluição decorrente dos automóveis, como também de comidas que são comercializadas nas calçadas. Essa variedade de odores foi enfatizada pelo deficiente como sendo comum a espaços como esse, que caracterizam-se pela existência de inúmeras circulações e atividades. O clima do espaço foi percebido como sendo quente, apesar de o deficiente visual notar o clima como normal para os padrões natalenses. 
Vale frisar que no percurso passou-se por duas ruas que ficam próximas da Avenida Senador Salgado Filho, a Antônio Basílio e a Dr. José Gonçalves. Nessas ruas havia menos circulação de veículos, o que foi prontamente percebido pelo deficiente visual. Ele fez questão de frisar que também nessas ruas não há apropriação para a locomoção de deficientes visuais, bem como para outros deficientes.

Por fim, a compreensão do primeiro espaço por ele vivenciado é expressa com os seus próprios dizeres:

é um espaço destinado à circulação de carros e pessoas, que sempre estão indo para outros espaços. Destaco a locomoção muito dificultosa para um deficiente visual, por causa da falta de sinais sonoros, dos desníveis das calçadas e do grande barulho provocado pelos carros, que faz com que eu não consiga perceber facilmente a presença de pessoas.

\subsubsection{SEGUNDO TRAJETO}

O segundo espaço visitado difere bastante do primeiro. É um espaço fechado, em que não há o barulho que havia no primeiro, decorrente da grande circulação de automóveis, com clima e odores também bastante diferentes dos que se faziam presentes no espaço anterior. Esse segundo espaço é o Shopping Midway Mall, que fica localizado na Avenida Senador Salgado Filho, bem próximo do CEFETRN.

Utilizando-se da audição, o deficiente visual percebeu imediatamente grandes diferenças desse espaço em relação ao primeiro. Disse perceber músicas e, com a inexistência do barulho dos automóveis, passos de pessoas.

Caracterizou o clima do espaço como sendo mais ameno em relação ao do primeiro, em função do condicionamento do ar que há dentro do local. Declarou sentir luminosidade nesse espaço, o que pode ser decorrente da apropriação de tonalidade de cor (branca) das paredes e do piso desse, facilitando essa percepção.

Em função do aplainamento do piso e da adequação sonora do espaço, afirmou que a sua locomoção nesse é menos difícil do que no primeiro. Todavia, destacou que a locomoção no shopping torna-se complicada quando há grande presença de pessoas circulando nesse, o que não acontecia no momento da visita. Além disso, declarou não gostar desse segundo espaço, por sentir receio de quebrar algum objeto quando for tocá-lo ou quando estiver locomovendo-se. Citou as vitrines como sendo as grandes vilãs de um deficiente visual dentro de um shopping, em função de impedirem o trabalho tátil e dificultarem a sua locomoção, por serem de vidro, facilmente podendo ser quebradas.

Os odores percebidos também foram vários, em função da grande variedade de lojas existentes no espaço. Com isso, foram sentidos cheiros de comidas, roupas, perfumes, livros, dentre outros elementos.

Em suma, a compreensão espacial acerca desse espaço foi a seguinte: “é um espaço bastante diferente do primeiro, sendo destinado ao trabalho e a diversão das pessoas”. 


\subsubsection{TERCEIRO TRAJETO}

O último espaço vivenciado no estudo difere bastante dos outros. É um espaço em que se preza pela conservação ambiental, sendo o maior parque de conservação ambiental urbano do Brasil. Esse espaço é o Parque das Dunas. Este é constituído por um bosque, denominado de Bosque dos Namorados, e por várias trilhas. O estudo com o deficiente nesse espaço foi todo feito no bosque, em função de não se ter agendado e preparado com antecedência a realização de alguma trilha. Destaca-se que a ausência da realização de alguma trilha no estudo não retirou a riqueza das percepções do aluno acerca desse espaço.

Logo de início, através do sentido da audição, o deficiente visual percebeu que o espaço possui inúmeras e intensas diferenças dos outros já visitados, dizendo ser esse "mais calmo em relação aos dois primeiros". Declarou ouvir cantos de pássaros e perceber a presença de pessoas conversando e trabalhando.

Ele utilizou-se bastante de seu tato para conhecer diversas espécies de árvores, como também para tocar por diversas vezes o solo do espaço. Em função de ser um local em que há o contato direto dos homens com a natureza, o deficiente afirmou que esse lhe passa uma sensação de "limpeza e conforto", destacando que se sente bem quando está em espaços como o visitado.

Os odores percebidos foram vários, como os de vegetação, de terra e de frutos. O clima foi percebido como sendo mais agradável do que os dos outros espaços, sendo que o deficiente visual declarou perceber mais o vento nesse espaço do que nos outros dois, inter-relacionando essa sua percepção à grande presença de árvores nesse.

Em relação a sua locomoção, destacou que a tranqüilidade do espaço a torna conseqüentemente mais aprazível. Todavia, destaca-se a falta de apropriação do Parque das Dunas para a locomoção de deficientes visuais, em função da quase inexistência de rampas e de referenciais de orientação. Por muitas vezes, o deficiente sentiu sérias dificuldades para subir e descer degraus que dão acesso a vários pontos do parque, o que poderia ser evitado se esses degraus fossem substituídos por rampas.

Por fim, destaca-se a compreensão desse espaço pelo deficiente visual: "é um espaço para as pessoas conhecerem mais a natureza, para terem um contato com esta, o que está difícil ultimamente, como também para o lazer das pessoas”.

No quadro 01 são mostradas ilustrações sobre as vivências do deficiente visual nos três trajetos.

\subsection{CONCEITUAÇÕES}

Toda ciência é perpassada por atividades que inter-relacionam experiências (vivências) com reflexões. A Geografia não difere dessa lógica. As experiências são responsáveis pelo enriquecimento de descrições nas ciências, e as reflexões trazem fortalecimento teórico, isto é, conceitual para o meio científico. Dessa maneira, diz-se que teoria e experiências são fatores indissociáveis.

O estudo em tela trouxe em um primeiro momento o relato de experiências vividas por um deficiente visual, as quais revelaram as suas percepções e compreensões acerca de 
diferentes espaços geográficos. Todavia, é necessário também conhecer as conceituações de espaço geográfico expressas por ele antes e depois das experiências. Para isso, foram feitas duas indagações ao deficiente antes e depois das vivências dos diferentes espaços: o que é espaço geográfico? Você acredita que todos os espaços são iguais?

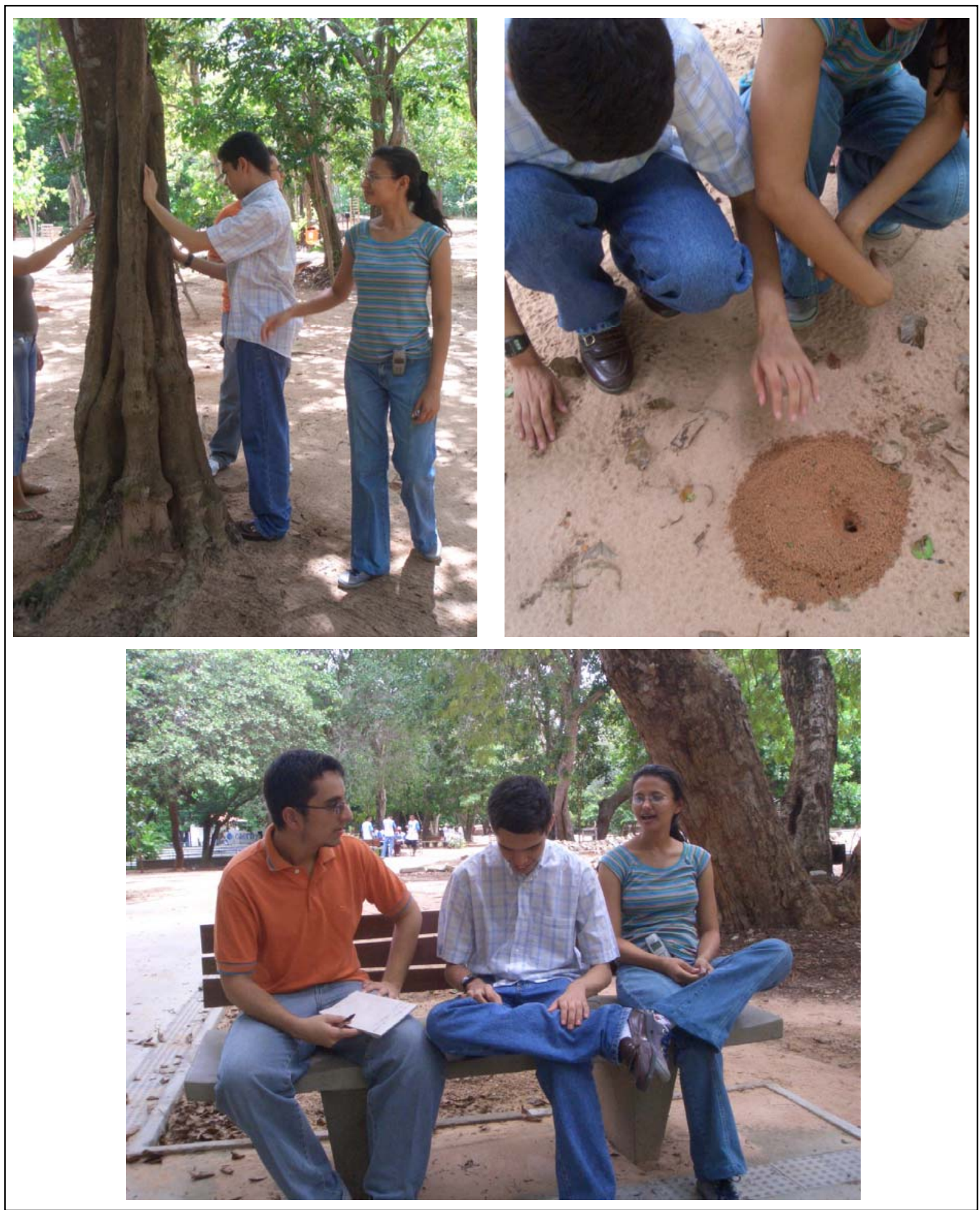

QUADRO 01: ILUSTRAÇÕES MOSTRANDO MOMENTOS DAS VIVÊNCIAS ESPACIAIS REALIZADAS COM O DEFICIENTE VISUAL, 2006. 
O fato dele responder essas indagações antes e depois das experiências revela se a sua compreensão espacial alterou-se com as vivências de diferentes estruturas espaciais. Destaca-se que o objetivo com essas indagações é o de mensurar sobre as reflexões espaciais do deficiente visual antes e depois de suas experiências.

Antes de vivenciar os três espaços geográficos, ele afirmou que o espaço é “algo utilizado pela Geografia, sendo bem geral, incluindo o urbano”. Vê-se que ele já tinha consciência da importância do espaço para os estudos geográficos, além de destacar a complexidade espacial quando diz que esse é "bem geral”. Mensurou também para o espaço que recebe as maiores atenções contemporâneas, em função de abarcar os mais intensos avanços e problemas das sociedades, no caso o urbano.

Ao ser indagado se todos os espaços são iguais, respondeu: "Não. Os espaços são diferentes, até mesmo nas suas representações em mapas. Os espaços também diferenciamse pela sua natureza. É interessante essa diferença, porque não teria graça se tudo fosse do mesmo tamanho".

Nessa resposta, ele demonstrou compreender que existem diferenças entre os espaços geográficos, destacando como elementos explicitantes dessas diferenças as representações espaciais em mapas, a natureza (vegetação, relevo, clima etc) e o tamanho dos espaços. Nota-se que o deficiente não demonstrou compreender o porquê realmente de os espaços serem diferentes entre si, mensurando apenas para os elementos naturais, de tamanho e representação, e não para o habitar, o experimentar e o produzir dos homens, o que também é importante para as configurações bem diferenciadas de cada espaço.

Posteriormente às experiências, o deficiente visual declarou ter (re)formulado seus pontos de vista em relação aos espaços geográficos, alterando, com isso, as suas conceituações. Sobre o que seria o espaço geográfico, ele disse: "é tudo aquilo que o homem altera e produz de acordo com o que ele necessita. Tudo é espaço geográfico”. Vêse que a compreensão espacial dele, após as experiências, explicita com veemência o humano no espaço geográfico, citando esse como sendo o produto das alterações dos homens de acordo com as suas necessidades. Além disso, quando diz que "tudo é espaço geográfico”, ele revela compreender que todos os espaços são hoje alterados pelos homens, sendo, portanto, humanizados, isto é, geográficos.

Em relação a indagação de que se todos os espaços são iguais, a resposta foi a seguinte: "Não. Em função dos elementos naturais de cada espaço e das diferentes necessidades dos homens, que os levam a produzirem vários espaços”. No primeiro momento, ele também disse que os espaços não são iguais, citando como elementos explicitadores disso as representações em mapas, os elementos naturais e o tamanho dos espaços. Após as experiências é notável o enriquecimento da sua compreensão espacial, que passa a destacar também como elementos importantes para a explicação das diferenças entre os espaços, além dos naturais, dos representacionais e de tamanho, os humanos, dizendo que as diversas necessidades dos homens, isto é, suas diversas vivências, os levam a alterar (produzir) diferentemente os espaços.

Com isso, destaca-se a (re)formulação de conceituações do deficiente visual acerca do espaço geográfico, dada com a indissociável relação das suas experiências com as suas reflexões. 


\section{CONSIDERAÇÕES FINAIS}

Após as considerações realizadas no desenvolvimento do estudo, é válido trazer à baila, neste encerramento, algumas reflexões importantes presentes no trabalho.

Primeiro, é válido destacar o determinismo de algumas concepções geográficas em relação às percepções humanas. Essas concepções colocam o sentido da visão como sendo o principal para se obter riqueza e significância nas percepções espaciais. Contudo, não se pode declarar que a visão é o sentido perceptivo mais importante para os homens, porque se estará excluindo o importante papel de outros sentidos para a compreensão espacial, como o da audição, do olfato, do tato e do paladar. Esse pensamento é explicitamente confirmado quando se analisa aqui as significativas percepções espaciais de um deficiente visual, dadas através da ação conjunta dos seus sentidos.

Também é imprescindível atentar para o fato de que se deve considerar indissociavelmente, em trabalhos científicos, teorias e práticas. Nenhuma teoria é significativa sem aplicabilidade, sendo que a lógica teoria-prática desencadeia enriquecimento para todo o meio científico.

Destaca-se também a necessidade de os geógrafos atentarem mais para estudos que tragam as compreensões espaciais das minorias (deficientes, desfavorecidos etc), até porque são essas que geralmente vivenciam com maior intensidade o espaço, podendo dar contribuições imensas à evolução da ciência geográfica.

Por fim, espera-se que o estudo em tela desencadeie outros, seja pela necessidade de aprofundar as reflexões aqui tecidas, seja pela necessidade de se efetuar críticas construtivas a essas reflexões.

\section{REFERÊNCIAS}

ALMEIDA, R. D. de ; PASSINI, E. Y. O espaço geográfico: ensino e representação. São Paulo: Contexto, 1989.

BETTANINI, T. Espaço e ciências humanas. Rio de Janeiro: Paz e Terra, 1982.

GOMES, P. C. da C. Geografia e Modernidade. Rio de Janeiro: Bertrand Brasil, 1996.

HERNANDEZ, F. Cultura visual, mudança educativa e projeto de trabalho. Tradução de Jussara Haubert Rodrigues. Porto Alegre: Artes Médicas Sul, 2000.

MORAES, A. C. R. Meio ambiente e ciências humanas. São Paulo: Editora Hucitec, 1994.

OLIVEIRA, L. Ainda sobre a percepção. I Colóquio Nacional de Pós-Graduação em Geografia. A epistemologia da Geografia Contemporânea face aos desafios da sociedade global. Textos básicos relativos aos temas das mesas redondas. Programa de Pós-Graduação. Mestrado em Geografia. UFPR. Nov. 2001. 
RELPH, E. C. As bases fenomenológicas da Geografia. Banco de dados do Departamento de Geografia da Universidade Federal do Rio Grande do Norte (UFRN). Reg. 1411. Data: 21/07/1988. p. 01-25.

SANTOS, M. A natureza do espaço: técnica e tempo, razão e emoção. São Paulo: Hucitec, 1996.

SANTOS, M. Por uma Geografia Nova: da crítica da Geografia a uma Geografia Crítica. São Paulo: Editora da Universidade de São Paulo, 2004.

TUAN, Y. F. Topofilia: um estudo da percepção, atitudes e valores do meio ambiente. São Paulo: Difel, 1980. 